\title{
REal worlD Effectiveness and Safety of Mepolizumab in a Multicentric Spanish Cohort of Asthma Patients Stratified by Eosinophils: The REDES Study
}

\author{
Christian Domingo Ribas ${ }^{1,2}$ (1) Teresa Carrillo Díaz ${ }^{3,4} \cdot$ Marina Blanco Aparicio $^{5} \cdot$ Eva Martínez Moragón $^{6}$. \\ David Banas Conejero ${ }^{7}$ M. Guadalupe Sánchez Herrero ${ }^{7}$ on behalf of the REDES Study Group
}

Accepted: 20 August 2021 / Published online: 29 September 2021

(c) The Author(s) 2021, corrected publication 2021

\begin{abstract}
Background The efficacy of mepolizumab is well documented in severe eosinophilic asthma (SEA), although the stringent selection criteria adopted by SEA clinical trials limits the generalizability of results.

Objective Our study evaluated the effectiveness and safety of mepolizumab in patients with SEA in Spain. The primary efficacy endpoint was the change in the rate of clinically significant asthma exacerbations 12 months after starting mepolizumab compared to the baseline rate in the 12 months prior to treatment. Patients were stratified by baseline blood eosinophil counts. Methods We conducted a multicentric observational cohort study of SEA patients treated with mepolizumab across 24 specialized hospital asthma units in Spain. Severe exacerbation rate, lung function, oral corticosteroid use (OCS) and asthma control test (ACT) were retrospectively collected and compared during the 12-month pre- and post-mepolizumab treatment. Adverse events were also investigated.

Results A total of 318 patients with SEA were included (mean age: 56.6 years, $69.2 \%$ female). Exacerbation rates decreased by $77.5 \%$, and $50.6 \%$ of patients did not suffer any exacerbations during the 12 months of treatment. The difference in forced expiratory volume in $1 \mathrm{~s}$ (FEV1) pre- and post-bronchodilator after starting mepolizumab was $0.21(0.46) \mathrm{L}(95 \%$ CI 0.14-0.27) $(p<0.001)$. Exacerbations and lung function significantly improved across all eosinophil subgroups. Among the 98 patients on OCS, $47.8 \%$ were able to discontinue this treatment and the mean daily dose was decreased by $59.9 \%$. The baseline ACT score was 14.1, increasing by a mean (SD) of 6.7 points (1.9) at 12 months. Adverse events related to mepolizumab were uncommon.

Conclusions This real-world study of SEA patients confirms that mepolizumab is effective in reducing clinically meaningful exacerbations, improving lung function, and decreasing OCS dependence and mean OCS dose at 12 months, irrespective of baseline eosinophil counts.
\end{abstract}

The members of "on behalf of the REDES Study group" is present in the Acknowledgements section.

Christian Domingo Ribas

cdomingo@tauli.cat

Extended author information available on the last page of the article 


\section{Key Points}

Pivotal studies and post hoc analyses of these studies have shown that mepolizumab is effective at eosinophil values of 150 cells/ $\mu \mathrm{L}$ and above. Whether these benefits are also maintained in real life is of interest.

REDES is a real-life study performed in Spain that evaluated the effectiveness and safety of mepolizumab in severe eosinophilic asthma that incorporates a prespecified stratification by blood eosinophil counts for outcomes analysis.

Mepolizumab reduced severe exacerbations and oral corticosteroid consumption, and improved asthma control. These benefits occurred irrespective of baseline eosinophil counts.

No severe adverse events related to mepolizumab were reported.

\section{Introduction}

Severe asthma encompasses a heterogeneous group of patients, with an estimated prevalence of $7.7 \%$ among individuals with asthma [1], which implies a substantial use of healthcare resources. There is an increasing consensus that the control of severe asthma is a major unmet need. The ERS/ATS task force defines severe asthma as a disease that, after asthma diagnosis is confirmed and co-morbidities addressed, requires treatment with high-dose inhaled corticosteroids plus a second controller and/or systemic corticosteroids to prevent it from becoming uncontrolled, or that remains uncontrolled despite this therapy [2-4].

Knowledge of the pathophysiology of severe asthma has improved during the last decade, and significant contributions on characterizing phenotypes have emerged from severe asthma cohorts and patient registries [5-7]. Adequate identification and management of these patients is key to preventing disease exacerbations and improving healthrelated quality of life. In this sense, the identification of eosinophilic asthma patients, which represent most of the type 2 asthma patients, is undoubtedly an increasingly relevant aspect of the asthma therapeutic approach [5, 8].

Mepolizumab, the first approved anti-IL-5 monoclonal antibody, binds to and blocks IL-5, a key factor in the regulation of the growth, differentiation, activation and survival of eosinophils. Several clinical trials have shown its efficacy in reducing exacerbations (MENSA) and oral corticosteroid use
(OCS) (SIRIUS), and improvement in quality of life (QoL), asthma control and lung function (MUSCA) [9-11]. It has also been shown to be effective as an alternative therapy for a group of patients not optimally controlled on omalizumab (OSMO) [12]. However, whilst the efficacy of mepolizumab is well documented, real-life data from independent sources on its effectiveness are currently limited, although growing through case series and global cohorts [13, 14]. Also, several single-centre real-life studies have shown evidence of the effectiveness of mepolizumab [15-18]. Moreover, the stringent selection criteria adopted by clinical trials in general and by monoclonal antibody development programs in severe asthma are highly restrictive [19].

The threshold of peripheral blood eosinophils at which anti-IL5 drugs are effective has been widely discussed in the literature. Pivotal studies and post hoc analyses of these studies show that mepolizumab is effective at eosinophil values of 150 cells/ $\mu \mathrm{L}$ and above. Whether these benefits are also maintained in real life is of interest [9].

As a result, we conducted a study to comprehensively evaluate the REal-worlD Effectiveness and Safety of mepolizumab in severe eosinophilic asthma (SEA), the REDES study. REDES incorporates two aspects: a prespecified stratification by blood eosinophil counts for outcomes analysis, and the fact that it has been performed in a Southern European patient population.

\section{Methods}

\subsection{Design and Study Population}

We conducted a phase IV, multicentric observational cohort study of severe eosinophilic asthma patients treated with mepolizumab across 24 geographically distributed Asthma Units in Spain. Sites were selected using a standard feasibility questionnaire ensuring they met the minimum relevant criteria for the study endpoints and geographic representativeness. Investigators needed to have followed up severe asthma patients regularly (i.e., every 6 months) for 12 months before mepolizumab initiation and at least 12 months after that date.

Investigators consecutively enrolled all eligible patients who met the inclusion criteria (Online Supplementary Material (OSM), Fig. 1). Data were retrospectively collected from patients' clinical records between December 2019 and July 2020 over an 8-month period.

Key inclusion criteria were a diagnosis of severe eosinophilic asthma in individuals aged $\geq 18$ years, with at least 12 months since the start of mepolizumab treatment, regardless of their treatment continuation at data inclusion time, with a regular follow-up since treatment initiation (at least every 6 months), and the availability of continuous follow-up 
Fig. 1 Patient flowchart

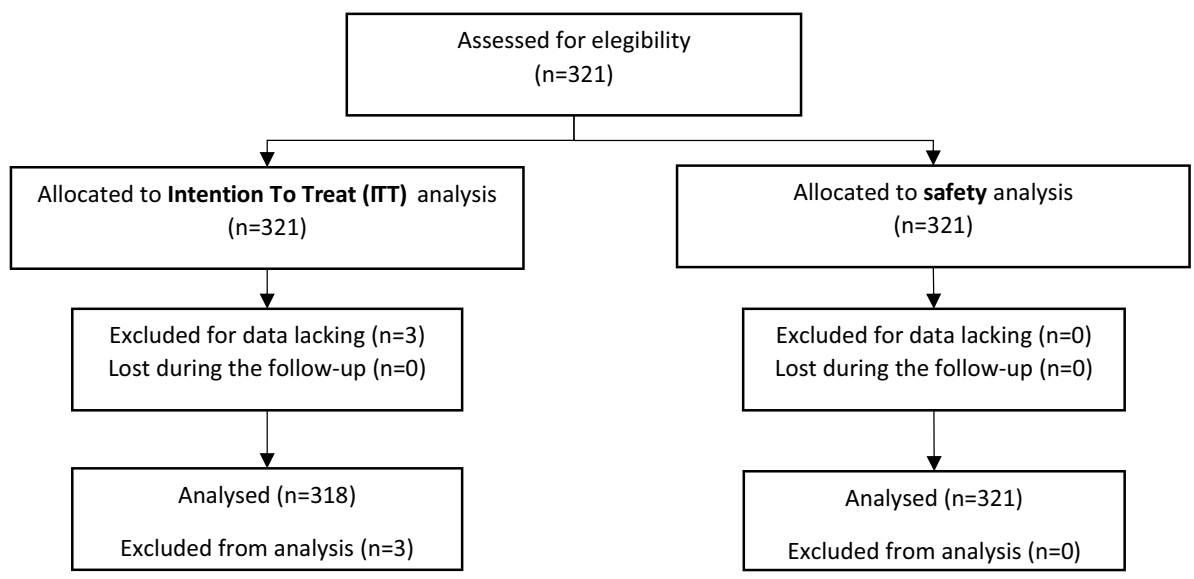

information in the 12 months before the introduction of mepolizumab. The key exclusion criteria were participation in an interventional asthma study in the 12 months prior or after initiating mepolizumab and missing key clinical information to define the primary endpoint.

\subsection{Outcome}

The primary outcome was the annual rate of clinically significant asthma exacerbations. These were defined as those exacerbations requiring the administration of a systemic corticosteroid for at least 3 days (or doubling the dose in patients on maintenance OCS), or if the patient had visited an emergency department or was hospitalized. Exacerbation rates in the 12 months before and after mepolizumab initiation were compared, and the percentage of reduction was calculated. For patients who discontinued treatment before the 6-month or 12-month timepoint, their last available measurement during treatment was used for the endpoint analyses. Two stratifications were carried out to baseline eosinophil levels: by ranges $(<150$ eosinophils/ $\mu \mathrm{L}, \geq 150$ eosinophils $/ \mu \mathrm{L}$ and $<300$ eosinophils $/ \mu \mathrm{L}, \geq 300$ eosinophils/ $\mu \mathrm{L}$ and $<500$ eosinophils/ $\mu \mathrm{L}$ and $\geq 700$ eosinophils/ $\mu \mathrm{L}$ at treatment initiation) and by lower thresholds: $\geq 150$ eosinophils/ $\mu \mathrm{L}, \geq 300$ eosinophils/ $\mu \mathrm{L}, \geq 500$ eosinophils/ $\mu \mathrm{L}$ and $\geq 700$ eosinophils/ $\mu \mathrm{L}$ at treatment initiation).

\subsection{Study Measurements}

Secondary outcomes included pre- and post-bronchodilator spirometric tests, compared at 6 months and 12 months after mepolizumab treatment to baseline values, changes in the number of eosinophils pre-/post-treatment were also assessed. In patients receiving a maintenance OCS dose at the time of mepolizumab initiation, changes in the average OCS daily maintenance dose were calculated pre-/postmepolizumab treatment. Symptom control was assessed using the Asthma Control Test (ACT) at baseline, at 6 months, and at 12 months after treatment initiation. Scores at 6 months and 12 months after mepolizumab treatment were compared to baseline.

We investigated the effect of baseline eosinophil count on exacerbations, ACT, and lung function following mepolizumab treatment. For this, patients were grouped according to their baseline blood eosinophil counts $(\geq 150$ cells $/ \mu \mathrm{L}, \geq 300$ cells $/ \mu \mathrm{L}, \geq 500$ cells $/ \mu \mathrm{L}$ and $\geq 700$ cells $/ \mu \mathrm{L}$ ), and baseline blood eosinophil ranges $(<150$ cells $/ \mu \mathrm{L}, 150-299$ cells $/ \mu \mathrm{L}$, $300-499$ cells $/ \mu \mathrm{L}, 500-699$ cells $/ \mu \mathrm{L}$ and $\geq 700$ cells $/ \mu \mathrm{L})$.

Safety was assessed by the collection and description of drug-related adverse events (AEs) during the study. The investigators determined the relationship of the AE to mepolizumab.

\subsection{Sample Population Size Calculation}

The study sample size was calculated according to the primary objective, the change in the number of exacerbations. A power analysis based on data from the COSMOS (MEA115661) open-label 1-year extension study was used to calculate the minimum sample size to measure a change in asthma exacerbation rate in real life. Patients on placebo during the MENSA study (MEA115588) experienced a 42\% exacerbation reduction during COSMOS, from 1.9 exacerbations/year to 1.1 exacerbations/year. The power analysis considered a sample size of 350 , after assuming $10 \%$ of missing data, meaning that we would need to include 320 patients. A one-sided test and alpha $=0.05$ showed that a sample of 320 patients had almost $100 \%$ power to detect the above-mentioned change in exacerbations.

\subsection{Statistical Analysis}

For the description of continuous variables, the mean (with 95\% CI), median, standard deviation (SD), interquartile range (IQR), minimum and maximum values were used. For the description of categorical variables, number and percentage within categories with $95 \%$ confidence intervals (CIs) were 
calculated. A paired two-tailed $t$-test was used for comparison of before/after periods for continuous variables and the McNemar test for categorical variables. To compare more than two groups, ANOVA was used. Exacerbation rates were modelled using a Poisson model, adjusted for treatment duration. A statistical significance level of 0.05 was used. All analyses were done using SAS version 9.2.

\section{Results}

\subsection{Overall Baseline Characteristics}

In total, 321 patients were enrolled, and 318 patients were eligible for the study. Three patients were excluded due to incomplete information on the study primary endpoint. There were no losses to follow up. The mean (SD) age of the population was $56.5(12.5)$ years. The gender distribution showed a predominance of women $(n=220,69.2 \%)$ (Table 1). The mean (SD) body mass index (BMI) was $28.6 \mathrm{~kg} / \mathrm{m}^{2}(5.50)$, and $72.8 \%$ of patients $(n=230)$ were overweight, obese or severely obese. Nasal polyposis was present in 147 patients (46.2\%), and allergic asthma was present in 193 patients $(60.7 \%)$. The diagnosis of allergic asthma was clinical and not always supported by allergy testing. Atopic sensitization was recorded in 131 patients, of which dust mites were the most common (53.9\% prick test and $45.3 \%$ specific IgE). Daily OCS maintenance therapy was used by 98 patients (30.8\%), and the mean (SD) dose was $12.1 \mathrm{mg} /$ day (10.0). Most patients (84.9\%, $n=237$ ) had poor asthma control at baseline (ACT score $<20$ ). Of the patients included in the study, $91.8 \%$ presented some co-morbidity, the most frequent being nasal polyposis $(46.2 \%)$, followed by chronic rhinosinusitis $(24.2 \%)$ and gastroesophageal reflux disease (GERD) $(21.2 \%)$. Allergic rhinitis was recorded in $21.7 \%$ of the cases (Table 1).

\subsection{Previous Treatment}

A total of 121 (38.2\%) of the patients were previously treated with omalizumab, and all of them switched to another biologic treatment due in most cases to a lack of effectiveness or inadequate control $(95 ; 78.5 \%)$ (Table 1 ).

At the time of the study visit, the mean duration of mepolizumab to discontinuation or to the date of the baseline visit (censored data) was 2.2 years. Two hundred and ninety-four $(92.5 \%)$ of the patients continued to receive mepolizumab; three patients $(0.9 \%)$ discontinued mepolizumab treatment 6 months, the main reason being inadequate control and adverse events (Table 2).
Table 1 Baseline overall characteristics of patients

\begin{tabular}{|c|c|}
\hline Baseline characteristics & $n=318$ \\
\hline Age mean (SD) & $56.6(12.5)$ \\
\hline Age at asthma diagnosis (years), mean (SD) & $34.1(17.9)$ \\
\hline \multicolumn{2}{|l|}{ Sex } \\
\hline Female & $220(69.2 \%)$ \\
\hline \multicolumn{2}{|l|}{ Ethnicity } \\
\hline Caucasian & $283(89.0 \%)$ \\
\hline BMI $\left(\mathrm{kg} / \mathrm{m}^{2}\right)$, mean $(\mathrm{SD})$ & $28.59(5.50)$ \\
\hline$<18.5$ & $2(0.6 \%)$ \\
\hline $18.5-25$ & $84(26.6 \%)$ \\
\hline $25-30$ & $122(38.6 \%)$ \\
\hline $30-35$ & $72(22.8 \%)$ \\
\hline$>35$ & $36(11.4 \%)$ \\
\hline Blood eosinophil count (cell/ $\mu \mathrm{L})$, mean (SD) & $710.2(836.8)$ \\
\hline Blood eosinophil count (cell/ $\mu \mathrm{L})$, median (IQR) & $550.0(360.0 ; 860.0$ \\
\hline$<150$ & $25(7.9 \%)$ \\
\hline $150-299$ & $23(7.3 \%)$ \\
\hline $300-499$ & $84(26.5 \%)$ \\
\hline $500-699$ & $61(19.2 \%)$ \\
\hline$\geq 700$ & $124(39.1 \%)$ \\
\hline \multicolumn{2}{|l|}{ Smoking habits } \\
\hline Never-smoker & $198(62.3 \%)$ \\
\hline Ex-smoker (> 6 months) & $106(33.3 \%)$ \\
\hline Smoker & $4(1.3 \%)$ \\
\hline Passive & $6(1.9 \%)$ \\
\hline Family history asthma & $92(31.9 \%)$ \\
\hline ACT, mean (SD) & $14.1(5.0)$ \\
\hline ACT not well controlled (ACT score $<20$ ) & $237(84.9 \%)$ \\
\hline OCS maintenance dose $(n=98)$, mean $(\mathrm{SD})$ & $12.1(10.0)$ \\
\hline Allergic asthma* & $193(60.7 \%)$ \\
\hline Atopic sensitization** & $131(41.5 \%)$ \\
\hline Positive cutaneous test & $102(32.1)$ \\
\hline Pollen & $44(43.1 \%)$ \\
\hline Animal epithelium & $35(34.3 \%)$ \\
\hline Mites & $55(53.9 \%)$ \\
\hline Positive specific $\operatorname{IgE}$ test & $64(20.1)$ \\
\hline Pollen & $32(50.0 \%)$ \\
\hline Animal epithelium & $23(35.9 \%)$ \\
\hline Mites & $29(45.3 \%)$ \\
\hline Previous omalizumab treatment & $121(38.2 \%)$ \\
\hline Time on treatment, median (IQR) & $24.0(12.0 ; 48.0)$ \\
\hline Discontinued due to inadequate control & $95(78.5 \%)$ \\
\hline Co-morbidities & $292(91.8 \%)$ \\
\hline GERD & $67(21.1 \%)$ \\
\hline Chronic rhinosinusitis & $77(24.2 \%)$ \\
\hline Allergic rhinitis & $69(21.7 \%)$ \\
\hline Nasal polyposis & $147(46.2 \%)$ \\
\hline Chronic rhinosinusitis and nasal polyposis & $34(10.7 \%)$ \\
\hline Atopic dermatitis & $4(1.3 \%)$ \\
\hline Hypersensitivity to NSAIDs & $42(13.2 \%)$ \\
\hline
\end{tabular}


Table 1 (continued)

\begin{tabular}{ll}
\hline Baseline characteristics & $n=318$ \\
\hline Bronchiectasis & $59(18.6 \%)$ \\
Anxiety & $62(19.5 \%)$ \\
Depression & $55(17.3 \%)$ \\
EGPA & $11(3.5 \%)$ \\
\hline
\end{tabular}

Values are $n(\%)$ unless otherwise specified

$B M I$ body mass index, $I g E$ immunoglobulin $\mathrm{E}, I Q R$ interquartile range, $S D$ standard deviation, EGPA eosinophilic granulomatosis with polyangiitis, $O C S$ oral corticosteroid, GERD gastroesophageal reflux disease, NSAID nonsteroidal anti-inflammatory drug, ACT asthma control test

*Allergic asthma $=$ the diagnosis of allergic asthma was a clinical diagnosis and collected from the patient's medical history

**Atopic sensitization includes recording of IgE positivity or prick test positivity to food or airborne allergen

\subsection{Exacerbations}

For the primary endpoint, the number of exacerbations was significantly reduced by $77.5 \%$ during the year postmepolizumab introduction $(p<0.001)$, which went from a mean (SD) of 4.5 (3.5) exacerbations per year during the pre-mepolizumab treatment period, to $1.0(1.4)$ in the postmepolizumab initiation period. All prespecified eosinophil subgroups reduced the mean number of exacerbations, irrespective of the eosinophil count (Fig. 2 and OSM Table 1). In the 12 months before mepolizumab treatment, a total of 91.8\% ( $n=292)$ of severe eosinophilic asthma patients had experienced an exacerbation. This proportion was significantly reduced to $49.4 \%(n=157)$ in the post-mepolizumab period ( $p$-value $<0.001$ ), with $50.6 \%$ of patients experiencing no exacerbations during the 12 months post-initiation (OSM Table 2 and OSM Fig. 2).

Exacerbations that required an emergency department visit/hospitalization decreased by $79.4 \%$ from 1.6 (2.08) to 0.3 (0.8) ( $p$-value < 0.001) (Fig. 3).

\subsection{Lung Function}

Figure 4 illustrates the evolution of the mean forced expiratory volume in $1 \mathrm{~s}$ (FEV1) pre- and post-bronchodilator use according to the different blood eosinophil subgroups. Overall, the mean FEV1 increased by $10.4 \%$ and a mean (SD) of $0.21 \mathrm{~L}(0.46)(p$ $<0.001)$. Changes in lung function in terms of the mean pre- and post-bronchodilator FEV1 are shown in OSM Table 3.

\subsection{Oral Corticosteroid Reduction}

A total of 98 patients required maintenance OCS treatment at baseline. Forty-three $(47.8 \%)$ of these patients were able to discontinue OCS after 12 months (Fig. 5 and
OSM Table 4), and the mean daily OCS maintenance dose decreased by $50.4 \%$ and $59.9 \%$ at 6 and 12 months, respectively, from $12.1 \mathrm{mg} /$ day at baseline to $6 \mathrm{mg} /$ day at month 6 and $4.9 \mathrm{mg} /$ day at month 12 (Fig. 5 and OSM Table 4). The baseline OCS maintenance dose was high ( $\geq 7.5 \mathrm{mg} /$ day $)$ in $57.1 \%$ of OCS-treated patients $(n=56)$ and decreased to $32.3 \%(n=30)$ and $28.9 \%(n=26)$ at 6 and 12 months, respectively.

\subsection{Symptom Control}

The ACT is a simple, patient-based, five-item tool for identifying patients with poorly controlled asthma, with a score that ranges between 5 and 25 [20]. A score ranging between 20 and 25 means that the patient is well controlled. A cutoff score of $\leq 19$ indicates patients with poorly controlled asthma [21]. A score between 16 and 19 is considered partially controlled asthma; a score $<16$ indicates the patient's asthma is uncontrolled. The minimally important difference (MID) for the ACT was established at three points [22]. The mean (SD) ACT score at baseline was 14.1 (5.0) and increased by a mean (SD) of 6.1 and 6.7 (1.9) points after 6 and 12 months of follow-up, reaching a final score of 20.3 and 20.8 , respectively. In $78.3 \%$ of patients, the pre-post difference was at least 3 points $(p<0.001)$ (Fig. 6 and OSM Table 4).

\subsection{Blood Eosinophil Counts}

The population treated with mepolizumab in Spain was highly eosinophilic, with $39.3 \%$ of the study sample having values over 700 cells $/ \mu \mathrm{L}$. The overall mean (SD) baseline eosinophil count was 710.16 cells $/ \mu \mathrm{L}$ (836.82), and treatment with mepolizumab reduced this to a mean (SD) of $124.74(457.74)$ cells $/ \mu \mathrm{L}(p<0.001)$ at 12 months, representing an $82.4 \%$ reduction.

\subsection{Safety}

During the study period, nine patients (2.8\%) out of the 321 registered AEs related to mepolizumab, reporting a total of 13 AEs related to mepolizumab (Table 3). The incidence of musculoskeletal and connective tissue disorders related to mepolizumab was $1.6 \%$. No severe AEs related to mepolizumab were reported.

The mean duration of mepolizumab until interruption or the date of data inclusion (whichever occurred first) was 2.2 years. At 6 months only three patients $(0.9 \%)$ had discontinued mepolizumab due to inadequate control $(n=2)$ and AEs $(n=1)$. Treatment persistence was $98.1 \%(n=312)$ at 12 months after mepolizumab initiation, and no further discontinuations due to AEs were observed. 
Table 2 Clinical characteristics at baseline (mepolizumab initiation)

\begin{tabular}{|c|c|}
\hline Variable & Total \\
\hline \multicolumn{2}{|l|}{ Continuation of mepolizumab treatment at study visit } \\
\hline Valid $n$ & $318(100 \%)$ \\
\hline No & $24(7.5 \%)$ \\
\hline Yes & $294(92.5 \%)$ \\
\hline \multicolumn{2}{|l|}{ Time (days) on mepolizumab treatment } \\
\hline Valid $n$ & 318 \\
\hline Mean (SD) & $789.34(413.86)$ \\
\hline Median & 728.5 \\
\hline$(\mathrm{P} 25 ; \mathrm{P} 75)$ & $(507.0 ; 952.0)$ \\
\hline$(\operatorname{Min} ; \max )$ & $(62.0 ; 2777.0)$ \\
\hline Missing $n$ & 0 \\
\hline \multicolumn{2}{|l|}{ Time (years) on mepolizumab treatment } \\
\hline Valid $n$ & 318 \\
\hline Mean (SD) & $2.16(1.13)$ \\
\hline Median & 2.0 \\
\hline$(\mathrm{P} 25 ; \mathrm{P} 75)$ & $(1.4 ; 2.6)$ \\
\hline$($ Min; $\max )$ & $(0.2 ; 7.6)$ \\
\hline Missing $n$ & 0 \\
\hline \multicolumn{2}{|l|}{ Discontinuation of mepolizumab at 6 months } \\
\hline Valid $n$ & $318(100 \%)$ \\
\hline No & $315(99.1 \%)$ \\
\hline Yes & $3(0.9 \%)$ \\
\hline \multicolumn{2}{|l|}{ Main reason for discontinuation at 6 months } \\
\hline Valid $n$ & $3(100 \%)$ \\
\hline Adverse events & $1(33.3 \%)$ \\
\hline Inadequate control & $2(66.7 \%)$ \\
\hline \multicolumn{2}{|l|}{ Months on treatment before discontinuation } \\
\hline Valid $n$ & 3 \\
\hline Mean (SD) & $3.00(1.73)$ \\
\hline Median & 2.0 \\
\hline$(\mathrm{P} 25 ; \mathrm{P} 75)$ & $(2.0 ; 5.0)$ \\
\hline$(\operatorname{Min} ; \max )$ & $(2.0 ; 5.0)$ \\
\hline \multicolumn{2}{|l|}{ Switching to another biologic treatment } \\
\hline Valid $n$ & $3(100 \%)$ \\
\hline Yes & $3(100 \%)$ \\
\hline \multicolumn{2}{|l|}{ Biologic treatment for switching } \\
\hline Valid $n$ & $3(100 \%)$ \\
\hline Benralizumab & $2(66.7 \%)$ \\
\hline Benralizumab (also stopped due to side effects) & $1(33.3 \%)$ \\
\hline
\end{tabular}

Valid $n$ number of valid patients included in the analysis

\section{Discussion}

Based in a diverse and heterogenous population, real-life studies provide complementary information to randomized clinical trials, supporting clinical decision-making by further understanding the effectiveness of a drug in real-world conditions and a more personalized treatment approach. The
REDES study included a heterogeneous population of 318 Spanish patients and a broad co-morbidity spectrum. It is striking that the percentage of allergic rhinitis is low (21\%), with a percentage of the allergic population around $50 \%$, compared to other studies that yield higher figures of up to $78 \%$ [20, 23]. The reason for the lower prevalence of rhinitis in REDES could be that, being a retrospective evaluation, mild rhinitis is often not recorded in medical records. The proportion of atopy was similar to that of MUSCA, and curiously, the proportion of nasal polyposis found in REDES was notably higher than the proportion found in the MUSCA trial [11]. The REDES study showed that mepolizumab was safe and effective in improving overall asthma control of severe eosinophilic asthma patients by significantly reducing severe exacerbations, OCS use and blood eosinophil counts, and improving lung function and asthma control scores (ACT). Significant improvements were evident by 6 months and persisted at month 12 .

The MENSA and MUSCA clinical trials demonstrated a clinically significant reduction in exacerbation rates by $53 \%$ and $58 \%$, respectively $[9,11]$. Within our sample, rates of clinically significant exacerbations were reduced during the mepolizumab treatment compared to the pre-mepolizumab period by $77.5 \%$. The percentage reduction in exacerbations within our study was closer to what was observed within the French nATU (temporary use authorisation) early access program to mepolizumab, in which an $86.2 \%$ reduction was observed at 12 and 24 months [24]. Other studies, smaller in size, based on real-world data have reported similar reductions in exacerbations [25, 27, 29]. This is relevant, as the frequency and severity of exacerbations has been associated with a decreased health-related quality of life [30, 31]. Realworld studies have also reported improvements in OCS use, lung function and asthma control in line with our findings [26, 28, 32].

A relatively high number of patients switched from omalizumab to mepolizumab compared to other reports [33]. It should be noted that for a decade omalizumab was the only biologic on the market. This undoubtedly led to the testing of anti-immunoglobulin (Ig) $\mathrm{E}$ in severe patients in indications that would be questionable today.

Mepolizumab clinical trial selection requirements concerning eosinophil peripheral blood counts were set at 150 cells $/ \mu \mathrm{L}$, with efficacy below this level remaining uncertain. However, low eosinophil counts $(<150$ cells $/ \mu \mathrm{L})$ are often encountered in clinical practice and are likely due to OCS use, which reduce blood eosinophils to normal or low levels, despite persistence of eosinophilic inflammation in patients with severe asthma. REDES included a prespecified stratification by blood eosinophil counts, and within our study, individuals who had counts below 150 eosinophils/ $\mu \mathrm{L}$ represented $7.9 \%$ of the population, who still received substantial benefit from mepolizumab add-on treatment. 
Fig. 2 Mean number of total exacerbations 12 months preand post-mepolizumab initiation by baseline eosinophil subgroups and thresholds

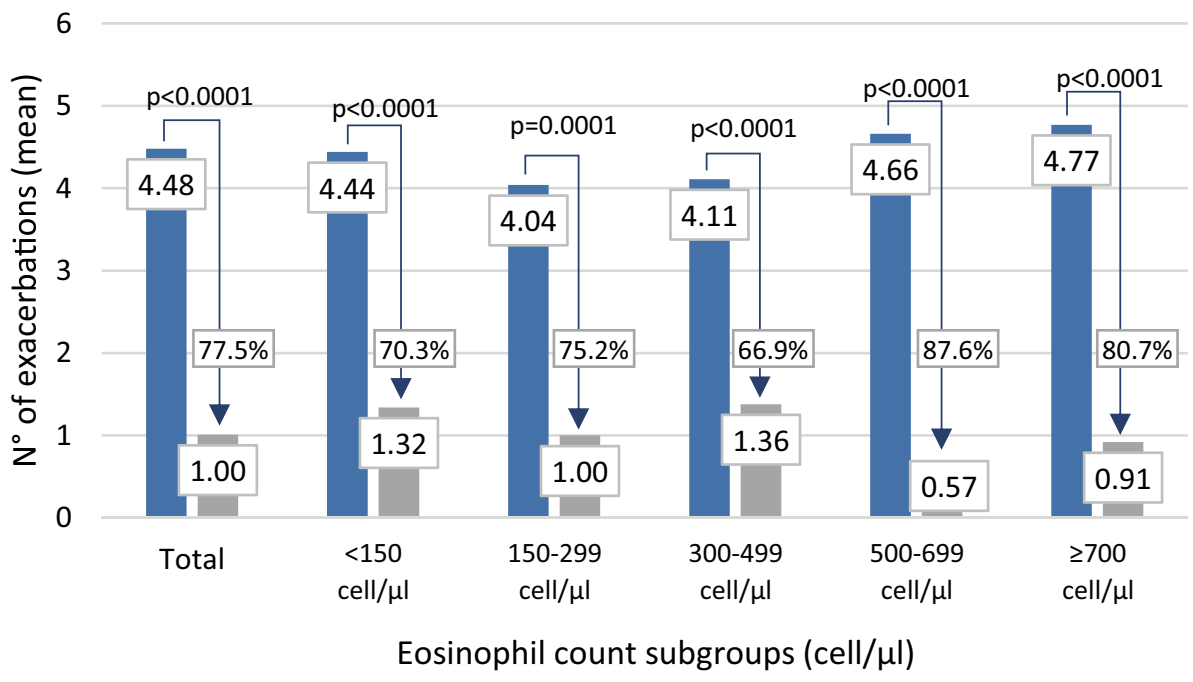

- Pre-Mepolizumab Post-Mepolizumab

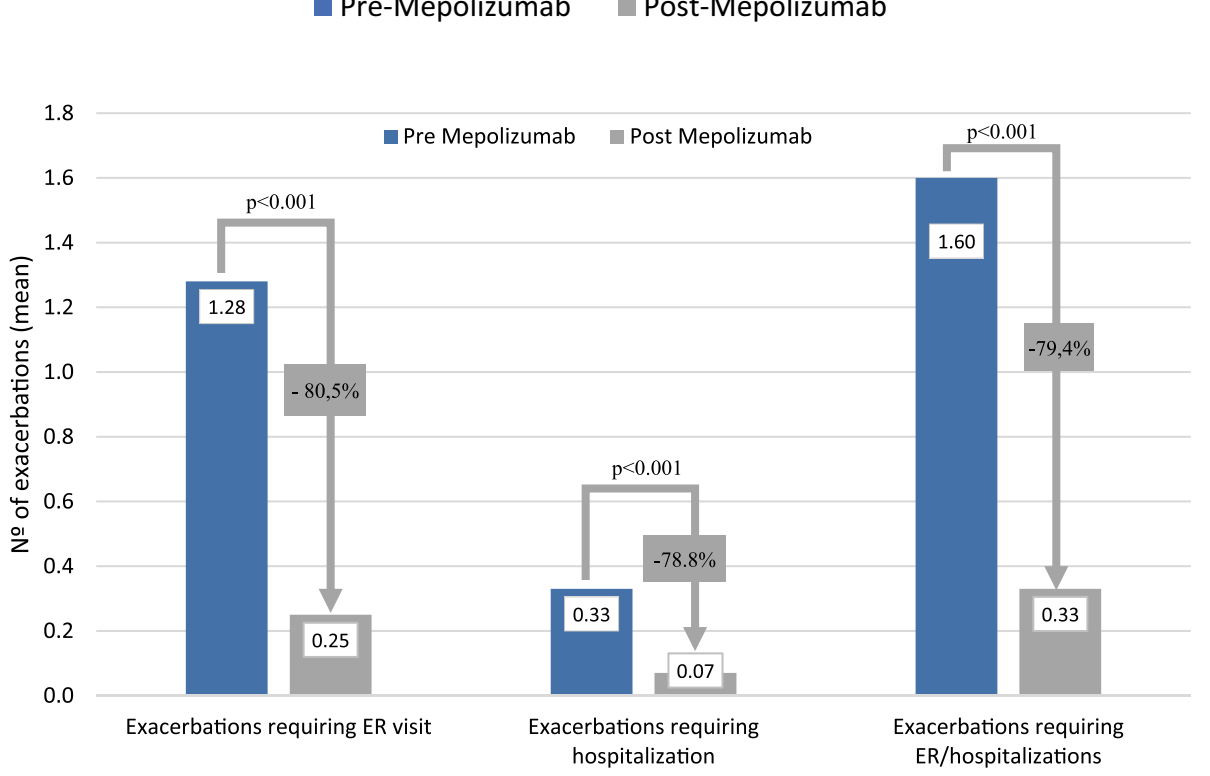

Fig. 3 Change in annual exacerbation rates pre- and post-mepolizumab initiation by exacerbation type. Three types of exacerbation types were considered: exacerbations requiring only corticosteroid, requiring emergency room (ER) visit and requiring hospitalization. Total exacerbations represent all exacerbations together, while exacerbations requiring ER/hospitalizations represent the sum of each individual category
Overall, while there was an observed tendency for greater improvements at higher baseline eosinophil counts, exacerbations and lung function improvements were observed irrespective of the baseline eosinophil counts. These findings are consistent with a post hoc analysis of the MENSA and DREAM studies, in which reductions in exacerbation frequency were observed for individuals with eosinophil counts $\geq 150$ cells $/ \mu \mathrm{L}$ and are relevant for clinical practice given current guidelines recommend mepolizumab use for patients with eosinophil counts $>150$ cells $/ \mu \mathrm{L}[8,34]$.

Amongst the 98 patients who required maintenance OCS at the start of mepolizumab, $34.4 \%$ of them discontinued OCS by 6 months and $47.8 \%$ did so by 12 months. Overall, at 12 months post-mepolizumab, the mean OCS maintenance dose was reduced by $59.9 \%$, in line with previous studies $[24,25]$. Furthermore, $53.6 \%$ of patients who were initially treated with an OCS maintenance dose $\geq 7.5 \mathrm{mg} /$ day were able to reduce their OCS dose below this mark, which is relevant in terms of reducing patients' risk category and subsequent treatment to prevent glucocorticoid-induced osteoporosis according to the most recent guidelines (OSM Table 4) [33, 35]. While timewise dose reductions in clinical trials were achieved earlier, this is likely explained by a more conservative management approach and less frequent visits in real-world practice [10, 24].

In line with previous studies, we found the frequency of drug-related adverse events was low. Additionally, treatment interruptions due to adverse events only occurred in one patient after 12 months [36]. 


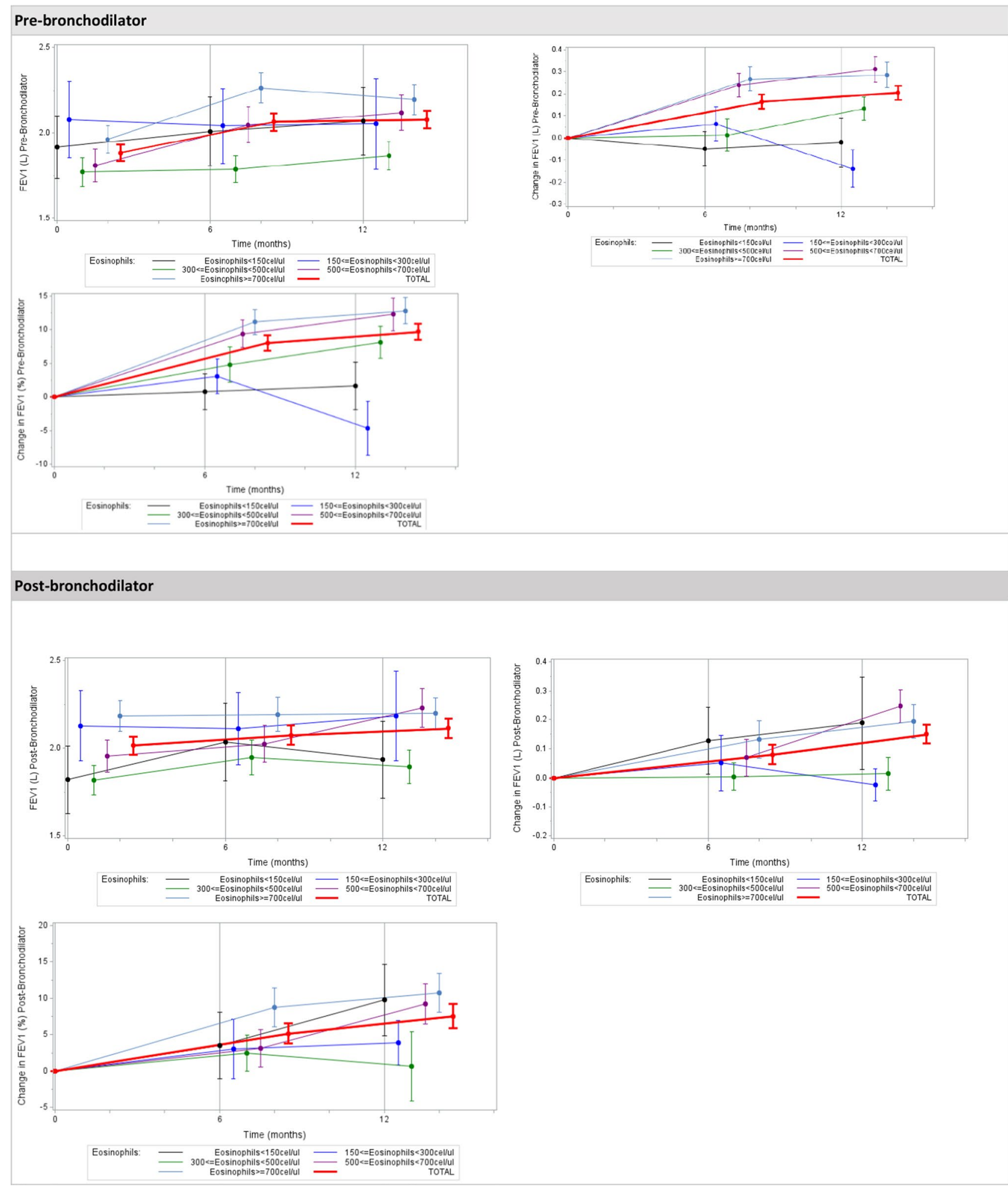

Fig. 4 Mean and standard error for evolution of forced expiratory volume in $1 \mathrm{~s}$ (FEV1) pre- and post-bronchodilator use according to expressed in (L) and as a percentage (\%). The change in FEV1 represents the mean difference from baseline at 6 and 12 months 


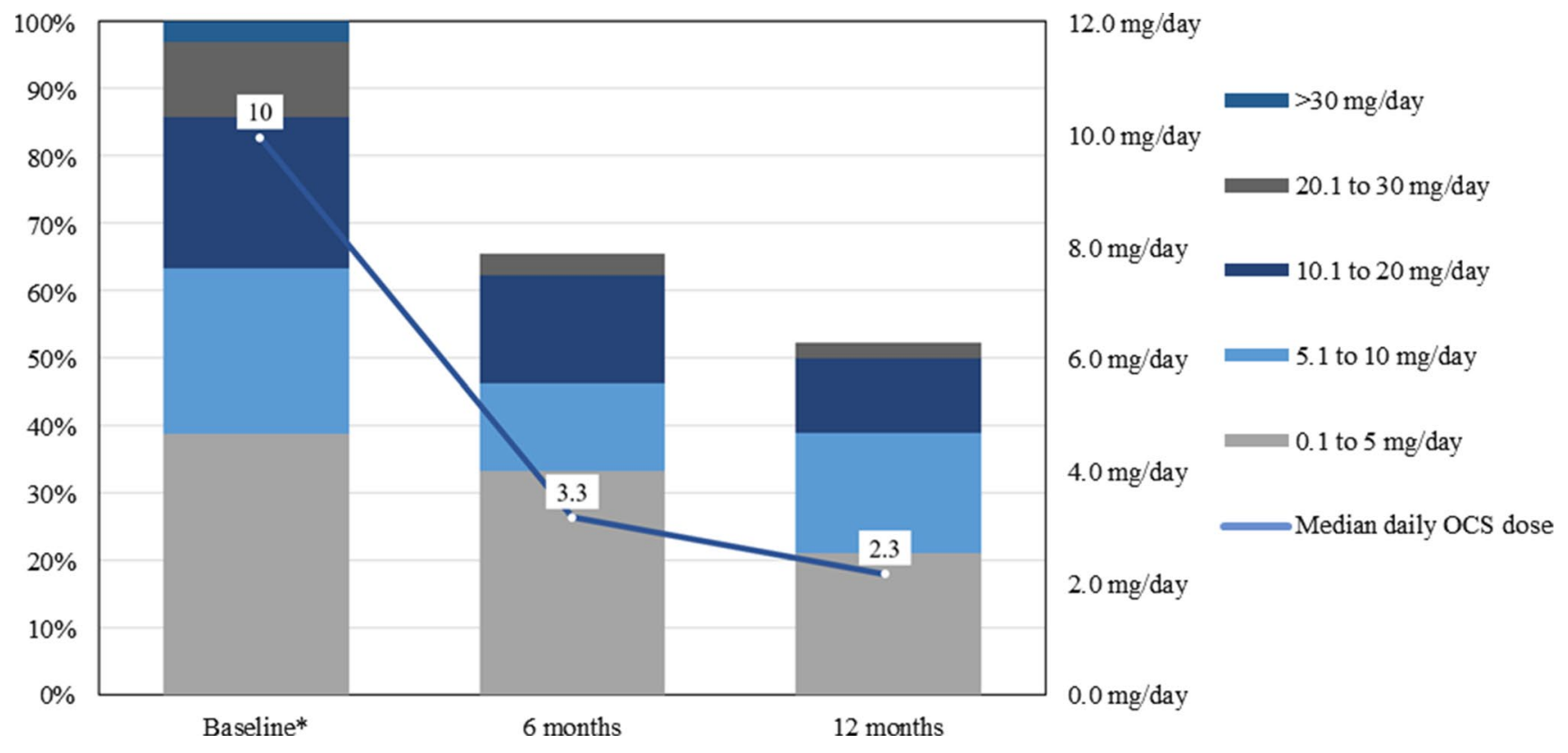

Fig. 5 Daily dose evolution of oral corticosteroid use (OCS; ranges and median daily dose of prednisone equivalent) in patients with maintenance corticosteroids at baseline. The left $Y$-axis represents the total percentages, which are based on the total number of patients with OCS treatment at baseline $(n=98)$. The right $Y$-axis represents the median OCS dose progression. The $X$-axis represents the three different assessment time points (baseline, 6 and 12 months). The colour gradients represent the OCS dose ranges, where the volume represents the percentage of patients within each range

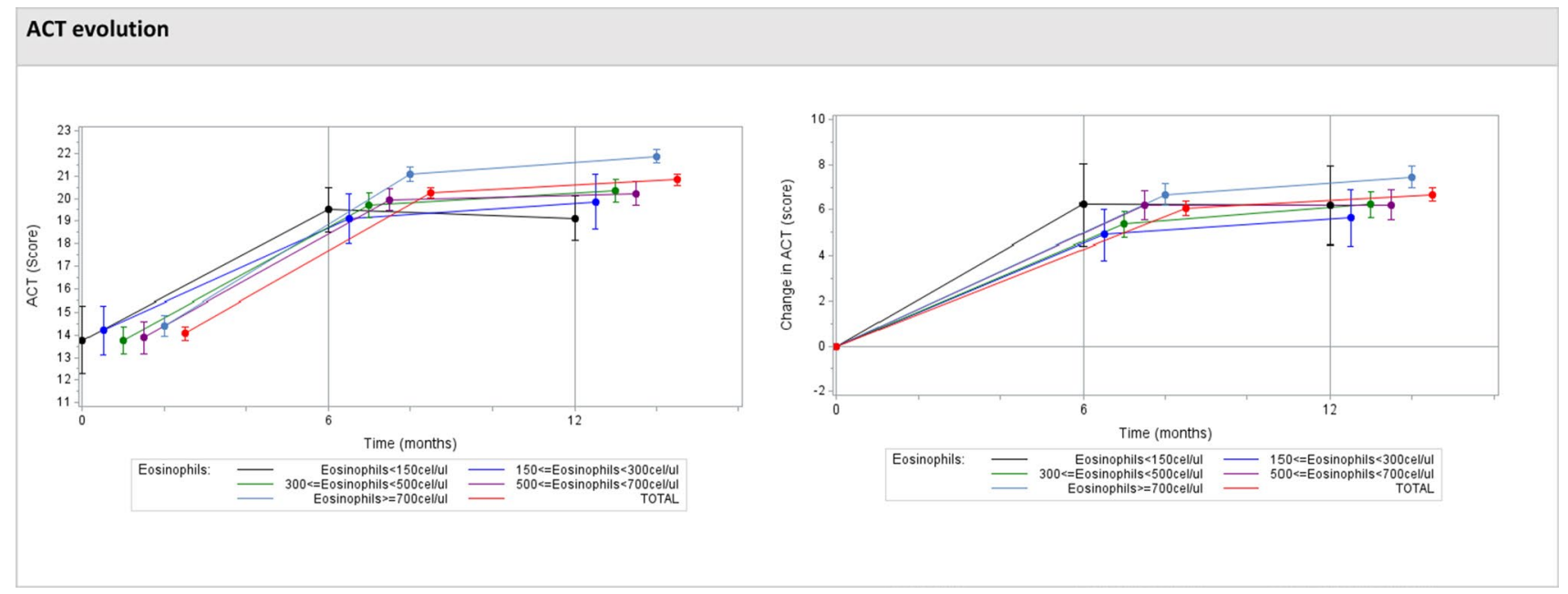

Fig. 6 Evolution from baseline in Asthma Control Test (ACT) scores after mepolizumab initiation. Evolution and change in the mean ACT scores over the three different assessment time-points (baseline, 6 and

\subsection{Strengths and Limitations}

Overall, the REDES study illustrates the management of severe eosinophilic asthma patients by asthma specialists in a real-world setting in Spain. Treatment recommendations were likely to guide prescription practices across participating sites through the therapeutic positioning report
12 months) according to blood eosinophil counts at baseline. ACT score $>19$ indicates well-controlled asthma

[37]. Additionally, treatment consensus guidelines on severe asthma management are followed among specialized asthma units in Spain and regularly updated [38].

This study's main limitation is its retrospective data collection, which may be subject to missing data and timevarying confounders. To minimize this aspect, the centres participating had specialised dedicated asthma units, the 
Table 3 Adverse drug-related events

\begin{tabular}{ll}
\hline & $n(\%)$ \\
\hline Overall & \\
Patients with adverse events related to mepolizumab* & $9(2.8 \%)$ \\
MedDRA Term* for adverse events & \\
Musculoskeletal and connective tissue disorders & $5(1.6 \%)$ \\
Arthralgia & $1(0.3 \%)$ \\
Arthromyalgia & $2(0.6 \%)$ \\
Bone pain & $1(0.3 \%)$ \\
Myalgia & $1(0.3 \%)$ \\
Nervous system disorders & $2(0.6 \%)$ \\
Headache & $2(0.6 \%)$ \\
Skin and subcutaneous tissue disorders & $2(0.6 \%)$ \\
Acneiform dermatitis & $1(0.3 \%)$ \\
Skin xerosis & $1(0.3 \%)$ \\
Gastrointestinal disorders & $1(0.3 \%)$ \\
Diarrhoea & $1(0.3 \%)$ \\
General disorders and administration site conditions & $1(0.3 \%)$ \\
Febricula & $1(0.3 \%)$ \\
Injury, poisoning and procedural complications & $1(0.3 \%)$ \\
Procedural headache & $1(0.3 \%)$ \\
Vascular disorders & $1(0.3 \%)$ \\
Deep vein thrombosis & $1(0.3 \%)$ \\
\hline
\end{tabular}

Table percentages are based on the total population $(n=318)$

MedDRA Medical Dictionary for Regulatory Activities

*Investigator's criteria

majority of which had a formal accreditation by the Spanish Society of Pulmonology (SEPAR) or the Spanish Society of Allergy (SEAIC).

Finally, the lack of a control group as part of the REDES study design must be considered in interpreting the safety data since this study uses pre-treatment as a comparison (baseline).

\section{Conclusions}

The REDES study helps advance patient care by providing useful information to guide clinical decision-making in patients with severe eosinophilic asthma. This real-life study of severe eosinophilic asthma patients treated with mepolizumab in Hospital Asthma Units of the Spanish National Health System confirms that mepolizumab was effective in reducing clinically significant exacerbations, improving lung function and decreasing OCS dependence and mean OCS dose irrespective of baseline blood eosinophil counts. The REDES study confirms in a real-life environment the benefits of mepolizumab in severe eosinophilic asthma patients.
Supplementary Information The online version contains supplementary material available at https://doi.org/10.1007/s40265-021-01597-9.

Acknowledgements We thank the REDES Study group members and collaborators who participated in the study: Mariana Muñoz and Héctor Cabrerizo from Hospital Bellvitge, Antonio Valero, Ebymar Arismendi, Irina Bobolea and Gemma López from Hospital Clínic, Celia Pinedo from Hospital Clínico San Carlos, Francisco Javier González-Barcala and Purificación Pérez-López-Corona from Hospital Clínico Santiago de Compostela; Jacinto Ramos-González and Javier Martín-Puentes from Hospital Clínico Universitario de Salamanca; Gregorio SotoCampos and Francisco Pérez-Grimaldi from Hospital de Jerez; Inmaculada Lluch from Hospital de La Ribera; Juan Luis García Rivero, Celia Gutiérrez-Villegas and Idoia Salinas-Garrido from Hospital de Laredo; Cleofé Fernández-Aracil from Hospital General Universitario de Alicante; Luis Puente-Maestu, Walther Iván Girón and Ángela GómezSacristán from Hospital General Universitario Gregorio Marañón; Miguel Díaz-Palacios and Ethel Ibáñez from Hospital La Fe; Irene De Lorenzo from Hospital Nuestra Sra. De la Candelaria; Ana Sogo, Daniel Ross-Monserrate and Elena Prina from Hospital Parc Taulí; Eusebi Chiner-Vives and Sandra Vañes from Hospital San Juan de Alicante; Rocío Díaz-Campos and Ismael García-Moguel from Hospital Universitario 12 de Octubre; Carmen Montero and María Fernández-Marrube from Hospital Universitario A Coruña; Tamara Hermida-Valverde and Anaís Enríquez from Hospital Universitario Central de Asturias; Nuria Marina-Malanda and Ana Gómez-Larrauri from Hospital Universitario de Cruces; Antonio García-Dumpiérrez, Rodolfo Castillo-Sainz, Nancy Ortega and Lourdes Almeida from Hospital Universitario Dr. Negrín; Luis Cabanes from Hospital Universitario Dr. Peset; Santiago Quirce, Javier Domínguez-Ortega, David Romero, Irene Hernández and Daniel Laorden from Hospital Universitario La Paz; Carolina Cisneros from Hospital Universitario La Princesa; Antolín López-Viña, Andrea Trisán and Teresa Caruana-Careaga from Hospital Universitario Puerta de Hierro; Ana Gómez-Bastero and Lucía Marín-Barrera from Hospital Virgen de la Macarena (list available in the Online Supplementary Material), Marta Rubio from IQVIA for her logistic support (in the form of contracting management, site training, database monitoring; funded by GSK) and Julieta Politi from IQVIA for her editorial support (in the form of writing assistance, development of initial draft, assembling tables and figures, collating authors' comments and referencing; funded by GSK).

\section{Declarations}

Funding This study was funded by GlaxoSmithKline (study number 213172).

Conflicts of interest CDR has received funding for travel or speaker fees from ALK, Almirall, AstraZeneca, Boehringer-Ingelheim, Chiesi, Esteve, Ferrer, GSK, Menarini, Novartis, Stallergenes and Pfizer. TCD has received speaker fees from ALK, Diater, GSK, LETI and Novartis. MBA has received speaker or consulting fees from ALK, AstraZeneca, Chiesi, GSK, Novartis, Teva and Zambón. EMM has received speaker or consulting fees from ALK, AstraZeneca, BIAL, Boehringer Ingelheim, Chiesi, GSK, Novartis, Teva, and Sanofi. DBC and MGSH are employees of GSK. CDR, TCD, MBA and EMM declare no specific conflicts of interest to report regarding this paper.

Ethics approval This study was performed in line with the principles of the Declaration of Helsinki and order SAS/3470/2009. Approval was granted by the Ethics Committee of Hospital La Princesa, Madrid, on 25 September 2019. 
Consent to participate Informed consent was obtained from all individual participants included in the study.

Consent for publication Informed consent obtained included the publication of participants' aggregate and anonymized health data.

Availability of data and material Not applicable.

Code availability Not applicable.

Author's contributions CDR, DBC, MGSH, TCD, MBA, EMM reviewed the literature and critically edited the manuscript. All authors read and approved the final version of the manuscript.

Open Access This article is licensed under a Creative Commons Attribution-NonCommercial 4.0 International License, which permits any non-commercial use, sharing, adaptation, distribution and reproduction in any medium or format, as long as you give appropriate credit to the original author(s) and the source, provide a link to the Creative Commons licence, and indicate if changes were made. The images or other third party material in this article are included in the article's Creative Commons licence, unless indicated otherwise in a credit line to the material. If material is not included in the article's Creative Commons licence and your intended use is not permitted by statutory regulation or exceeds the permitted use, you will need to obtain permission directly from the copyright holder. To view a copy of this licence, visit http://creativecommons.org/licenses/by-nc/4.0/.

\section{References}

1. Domingo Ribas C, Sogo Sagardia A, Prina E, Sicras Mainar A, Sicras Navarro A, Engroba Teijeiro C. Prevalence, characterization and costs of severe asthma in Spain (BRAVO 1). Eur Respir J. 2020;56(suppl 64):4639.

2. Chung KF, Wenzel SE, Brozek JL, Bush A, Castro M, Sterk PJ, et al. International ERS/ATS guidelines on definition, evaluation and treatment of severe asthma. Eur Respir J. 2014;43(2):343-73.

3. Plaza Moral V. GEMA(4.0). Guidelines for asthma management. Arch Bronconeumol. 2015;51(Suppl 1):2-54.

4. Hekking PW, Wener RR, Amelink M, Zwinderman AH, Bouvy ML, Bel EH. The prevalence of severe refractory asthma. J Allergy Clin Immunol. 2015;135(4):896-902.

5. Schleich F, Brusselle G, Louis R, Vandenplas O, Michils A, Pilette $\mathrm{C}$, et al. Heterogeneity of phenotypes in severe asthmatics: The Belgian Severe Asthma Registry (BSAR). Respir Med. 2014;108(12):1723.

6. The ENFUMOSA Study Group. The ENFUMOSA cross-sectional European multicentre study of the clinical phenotype of chronic severe asthma. European Network for understanding mechanisms of severe asthma. Eur Respir J. 2003;22(3):470-7.

7. Moore WC, Bleecker ER, Curran-Everett D, Erzurum SC, Ameredes BT, Bacharier L, et al. Characterization of the severe asthma phenotype by the National Heart, Lung, and Blood Institute's Severe Asthma Research Program. J Allergy Clin Immunol. 2007;119(2):405-13.

8. Global Initiative for Asthma. Global Strategy for Asthma Management and Prevention, 2021. www.ginasthma.org

9. Ortega HGLM, Pavord ID, Brusselle GG, FitzGerald JM, Chetta A, et al. Mepolizumab treatment in patients with severe eosinophilic asthma. N Engl J Med. 2014;371(13):1198-207.
10. Bel EH, Wenzel SE, Thompson PJ, Prazma CM, Keene ON, Yancey SW, et al. Oral glucocorticoid-sparing effect of mepolizumab in eosinophilic asthma. N Engl J Med. 2014;371(13):1189-97.

11. Chupp GBE, Albers F, Bratton D, Wang-Jairaj J, Nelsen L, Trevor J, Magnan A, Brinke A. Efficacy of mepolizumab add-on therapy on health-related quality of life and markers of asthma control in severe eosinophilic asthma (MUSCA): a randomised, doubleblind, placebo-controlled, parallel-group, multicentre, phase $3 \mathrm{~b}$ trial. Lancet Respir Med. 2017;5(5):390-400.

12. Chapman KRAF, Chipps B, et al. The clinical benefit of mepolizumab replacing omalizumab in uncontrolled severe eosinophilic asthma. Allergy. 2019;74(9):1716-26. https://doi.org/10.1111/all. 13850.

13. Enríquez-Rodríguez AI, Hermida Valverde T, Romero Álvarez P, López-González FJ, Gullón Blanco JA, Expósito Villegas AR, et al. Results in clinical practice in the treatment of severe eosinophilic asthma with mepolizumab: a real-life study. J Asthma. 2021:1-7. https://doi.org/10.1080/02770903.2021.1897835

14. Harrison T, Canonica GW, Chupp G, Lee J, Schleich F, Welte T, et al. Real-world mepolizumab in the prospective severe asthma REALITI-A study: initial analysis. Eur Respir J. 2020;56(4): 2000151.

15. Crimi C, Campisi R, Nolasco S, Cacopardo G, Intravaia R, Porto $\mathrm{M}$, et al. Mepolizumab effectiveness in patients with severe eosinophilic asthma and co-presence of bronchiectasis: a real-world retrospective pilot study. Res Med. 2021;185: 106491.

16. Crimi C, Campisi R, Nolasco S, Cacopardo G, Intravaia R, Nolasco S, et al. Real-life effectiveness of mepolizumab in patients with severe refractory eosinophilic asthma and multiple comorbidities. World Allergy Organ J. 2020;13(9): 100462.

17. Kavanagh JE, d'Ancona G, Elstad M, Green L, Fernandes M, Thomson L, et al. Real-world effectiveness and the characteristics of a "Super-Responder" to mepolizumab in severe eosinophilic asthma. Chest. 2020;158(2):491-500.

18. Kayser MZ, Drick N, Milger K, Fuge J, Kneidinger N, Korn S, et al. Real-world multicenter experience with mepolizumab and benralizumab in the treatment of uncontrolled severe eosinophilic asthma over 12 months. J Asthma Allergy. 2021;14:863-71.

19. Brown T, Jones T, Gove K, Barber C, Elliott S, Chauhan A, et al. Randomised controlled trials in severe asthma: selection by phenotype or stereotype. Eur Respir J. 2018;52(6): 1801444.

20. Nathan RA, Sorkness CA, Kosinski M, Schatz M, Li JT, Marcus P, et al. Development of the asthma control test: a survey for assessing asthma control. J Allergy Clin Immunol. 2004;113(1):59-65.

21. Schatz M, Sorkness CA, Li JT, Marcus P, Murray JJ, Nathan RA, et al. Asthma control test: reliability, validity, and responsiveness in patients not previously followed by asthma specialists. J Allergy Clin Immunol. 2006;117(3):549-56.

22. Schatz M, Kosinski M, Yarlas AS, Hanlon J, Watson ME, Jhingran $\mathrm{P}$, et al. The minimally important difference of the Asthma Control Test. J Allergy Clin Immunol. 2009;124(4):719-23.e1.

23. Leynaert B, Neukirch C, Liard R, Bousquet J, Neukirch F. Quality of life in allergic rhinitis and asthma. A population-based study of young adults. Am J Respir Crit Care Med. 2000;162(4 Pt 1):1391-6.

24. Taillé C, Chanez P, Devouassoux G, Didier A, Pison C, Garcia $\mathrm{G}$, et al. Mepolizumab in a population with severe eosinophilic asthma and corticosteroid dependence: results from a French early access programme. Eur Respir J. 2020;55(6): 1902345.

25. Montero-Pérez O, Contreras-Rey MB, Sánchez-Gómez E. Effectiveness and safety of mepolizumab in severe refractory eosinophilic asthma: results in clinical practice. Drugs Context. 2019;8: 212584 . 
26. Schleich F, Graff S, Nekoee H, Moermans C, Henket M, Sanchez $\mathrm{C}$, et al. Real-word experience with mepolizumab: does it deliver what it has promised? Clin Exp Allergy. 2020;50(6):687-95.

27. Bagnasco D, Caminati M, Menzella F, Milanese M, Rolla G, Lombardi $\mathrm{C}$, et al. One year of mepolizumab. Efficacy and safety in real-life in Italy. Pulm Pharmacol Ther. 2019;58: 101836.

28. Pertzov B, Unterman A, Shtraichman O, Shitenberg D, Rosengarten D, Kramer MR. Efficacy and safety of mepolizumab in a real-world cohort of patients with severe eosinophilic asthma. J Asthma. 2021;58(1):79-84.

29. Pelaia C, Crimi C, Pelaia G, Nolasco S, Campisi R, Heffler E, et al. Real-life evaluation of mepolizumab efficacy in patients with severe eosinophilic asthma, according to atopic trait and allergic phenotype. Clin Exp Allergy. 2020;50(7):780-8.

30. Luskin AT, Chipps BE, Rasouliyan L, Miller DP, Haselkorn T, Dorenbaum A. Impact of asthma exacerbations and asthma triggers on asthma-related quality of life in patients with severe or difficult-to-treat asthma. J Allergy Clin Immunol Pract. 2014;2(5):544-52.e1-2.

31. Pavord ID, Korn S, Howarth P, Bleecker ER, Buhl R, Keene ON, et al. Mepolizumab for severe eosinophilic asthma (DREAM): a multicentre, double-blind, placebo-controlled trial. Lancet. 2012;380(9842):651-9.

32. Farne HA, Wilson A, Powell C, Bax L, Milan SJ. Anti-IL5 therapies for asthma. Cochrane Database Syst Rev. 2017;9(9): Cd010834.
33. Carpagnano GE, Pelaia C, D'Amato M, Crimi N, Scichilone N, Scioscia G, et al. Switching from omalizumab to mepolizumab: real-life experience from Southern Italy. Ther Adv Respir Dis. 2020;14:1-13.

34. Ortega HG, Yancey SW, Mayer B, Gunsoy NB, Keene ON, Bleecker ER, et al. Severe eosinophilic asthma treated with mepolizumab stratified by baseline eosinophil thresholds: a secondary analysis of the DREAM and MENSA studies. Lancet Respir Med. 2016;4(7):549-56.

35. Buckley L, Guyatt G, Fink HA, Cannon M, Grossman J, Hansen KE, et al. 2017 American College of Rheumatology Guideline for the prevention and treatment of glucocorticoid-induced osteoporosis. Arthritis Rheumatol. 2017;69(8):1521-37.

36. Magnan A, Bourdin A, Prazma CM, Albers FC, Price RG, Yancey $\mathrm{SW}$, et al. Treatment response with mepolizumab in severe eosinophilic asthma patients with previous omalizumab treatment. Allergy. 2016;71(9):1335-44.

37. Agencia Española del Medicamento y Productos Sanitarios (AEMPS). Informe de posicionamiento terapéutico PT-mepolizumab/V1/27102016. 2016

38. Álvarez Gutiérrez FJ, Blanco Aparicio M, Plaza V, Cisneros C, García Rivero JL, Padilla A, et al. Documento de consenso de asma grave en adultos. Actualización 2020. Open Respir Arch. 2020;2(3):158-74.

\section{Authors and Affiliations}

\section{Christian Domingo Ribas ${ }^{1,2}$ (1) . Teresa Carrillo Díaz ${ }^{3,4} \cdot$ Marina Blanco Aparicio $^{5}$ - Eva Martínez Moragón ${ }^{6}$. David Banas Conejero ${ }^{7} \cdot$ M. Guadalupe Sánchez Herrero ${ }^{7}$ on behalf of the REDES Study Group}

1 Servei de Pneumologia, Corporació Sanitària Parc Taulí, Parc Taulí s/n, Sabadell, 08208 Barcelona, Spain

2 Universitat Autònoma de Barcelona (UAB), Barcelona, Spain

3 H. Universitario de Gran Canaria Doctor Negrín, Las Palmas de Gran Canaria, Spain

4 Universidad de Las Palmas Gran Canaria, Las Palmas de Gran Canaria, Spain
5 H. Universitario A Coruña, A Coruña, Spain

6 H. Universitario Doctor Peset, Valencia, Spain

7 Specialty Care Medical Department, GlaxoSmithKline, Madrid, Spain 